\title{
Voltage Analysis on MV/LV Distribution Networks with the Integration of DC Fast Chargers
}

\author{
Hasan Berkem Sonder, Liana Cipcigan, Carlos E. Ugalde-Loo \\ School of Engineering \\ Cardiff University \\ Cardiff, UK \\ HasanBerkemS@cardiff.ac.uk, Cipciganlm@cardiff.ac.uk, Ugalde-LooC@cardiff.ac.uk
}

\begin{abstract}
The development of ultra-low carbon emission electric vehicles (EVs) has been grown rapidly over the last years in response to the large share of greenhouse gas emissions contributed by the transportation sector. One of the main issues among EV drivers is range anxiety, which mainly results from the long charging battery durations. DC fast charging, the latest charging technology, aims to shorten charging duration; however, the success of e-mobility will be also related to the capacity of the distribution network to integrate the new EVs and their chargers. Specifically, the integration of EVs and DC fast chargers will increase the peak demand and may pose significant challenges for $\mathrm{MV}$ and $\mathrm{LV}$ distribution networks if adequate control measures are not implemented. This paper introduces a topology for the modelling and connection of a DC fast charger on a real MV/LV distribution network and ensures that the network operates within acceptable limits and that consumers connected to it are minimally affected. Simulation results show that DC fast chargers stress the $L V$ distribution network by causing grid congestions; however, local voltage control measures and a vehicle-to-grid technology can improve some of the grid-side challenges.
\end{abstract}

Keywords-Distributed generation, electric vehicles, fast charging, low voltage distribution network, vehicle-to-grid, voltage control

\section{INTRODUCTION}

The transportation sector produces a large share of greenhouse gas and particle emissions. The society is deeply concerned about the health and environmental impacts resulting from the dependence on fossil fuels. The replacement of internal combustion engine vehicles (ICEVs) with electric vehicles (EVs) is a vital solution to achieve the electrification of the transport sector while, at the same time, reduce the dependence on fossil fuels and save up to 2.3 tons of carbon dioxide annually [1, 2]. According to [3], the EV stock is projected to reach 230 million vehicles by 2030 . However, a limited capacity of the existing power networks, long charging durations and limited charging options for vehicles, and the high investment costs of EVs associated with battery prices are some of the main challenges to consider [4, 5]. The massive deployment of EVs may also significantly affect the operation and planning of medium voltage (MV) and low voltage (LV) distribution networks. To maintain a stable and secure system operation with the integration of EVs and their sophisticated chargers, it is of high importance to ensure acceptable voltage profiles and minimise network losses and overloading of network equipment $[6,7]$.

There are three main modes of EV charging. Level I (slowspeed) and Level II chargers (normal/medium-speed) are widely used and deployed at the residential level in AC. Level I and Level II chargers output a charging power of up to $3 \mathrm{~kW}$ and $20 \mathrm{~kW}$, respectively. Moreover, the duration of charging a fully depleted EV battery may take up to 15 hours and 4 hours using these charger modes, respectively [6, 8, 9]. This charging duration is relatively slow when compared to the gas refuelling speeds of ICEVs, and the aim is to shorten the charging duration by introducing a higher-level charging topology, namely, Level III or public DC fast/rapid chargers.

According to [10], Level III chargers help to improve customer satisfaction and reduce range anxiety among drivers (i.e., concern that the battery power may run out before a suitable charging point is reached) [10]. The development of Level III chargers will also increase access to public charging facilities, improve end-user experience, facilitate smooth traffic operation, and reduce the waiting and service time at stations $[11,12]$. However, Level III chargers operate at or higher voltages than $480 \mathrm{~V} \mathrm{DC}$ and require very high power to achieve fast charging. Because of this, these chargers will account for a large part of the total energy consumption and, hence, pose challenges for existing electric networks.

There is a limited amount of practical work analysing the integration, modelling, control and impacts of DC fast chargers on electrical distribution networks $[6,13]$. In the current literature, a greater focus is directed to whether the existing power networks can support the connection and operation of Level III chargers considering the ever-rising electricity demand and consumption. Several studies related to the charging of EVs in test networks can be found in the literature. The objectives of the studies vary, including analysing the effects of fast chargers on harmonics [14], voltage profiles and power losses [15, 16], comparing network losses at different EV penetration rates [16], investigating voltage fluctuations and voltage flicker with fast charging stations in power systems [17, 18], presenting an optimisation approach to find the optimal placing of fast charging stations [19], investigating the impacts of fast chargers on transformer loading [11], designing an optimal fast charging station in LV networks [7], and reviewing the impacts of vehicle-to-grid (V2G) technology on distribution systems [20].

In order to bridge the main research gap, this paper instead models a practical $\mathrm{MV} / \mathrm{LV}$ distribution network and investigates the dynamics and effects of modelling and connecting Level III DC fast chargers. The modelling and implementation of small-scale distributed generation (DG) units and V2G technology is presented to reduce the potential effects of fast chargers on distribution network operation and equipment. 


\section{LeVEl III Public DC FASt Charging Stations}

Level I and Level II charging is mainly performed at the residential level and, hence, these chargers are usually connected at the LV side of the distribution network. However, Level III public fast chargers operate at high DC voltages and draw larger powers from electrical grids. Therefore, DC fast charging stations are also connected at the MV level in distribution networks so that higher levels of charging power can be supplied to the point of connection [13, 21].

\section{A. Modelling and connection of DC fast chargers to grids}

There are three main stages when connecting a DC fast charging station to a distribution network (see Fig. 1). A suitable location and voltage level are initially chosen in the network. In this paper, a $50-\mathrm{kW}$ fast charger is connected to one of the $0.4 \mathrm{kV}$ busbars next to a commercial load by a threephase $0.4 / 0.69 \mathrm{kV}$ step-up transformer to achieve the charging level for the battery.

A bidirectional two-level three-phase voltage source converter (VSC) is then designed and connected to transform the AC voltage into a suitable DC voltage at the point of charging. This converter (see Fig. 2) is essential at connecting the charger to the network at a suitable voltage level. The VSC consists of six insulated-gate bipolar transistor (IGBT) switches (S1 - S6) that are controlled using pulse-width modulation (PWM), six anti-parallel diodes (D1 - D6) to enable current flow, and two capacitors (C) to reduce voltage ripple. Lastly, a DC/DC charger (see Fig. 3) with a buck-boost DC/DC converter and an equivalent battery model operating at $500 \mathrm{~V} \mathrm{DC}$ voltage is connected in series with the VSC to achieve the required charging voltage, current and power for the batteries of vehicles $[13,21]$. The rating of the charger equipment determines the duration of charging.

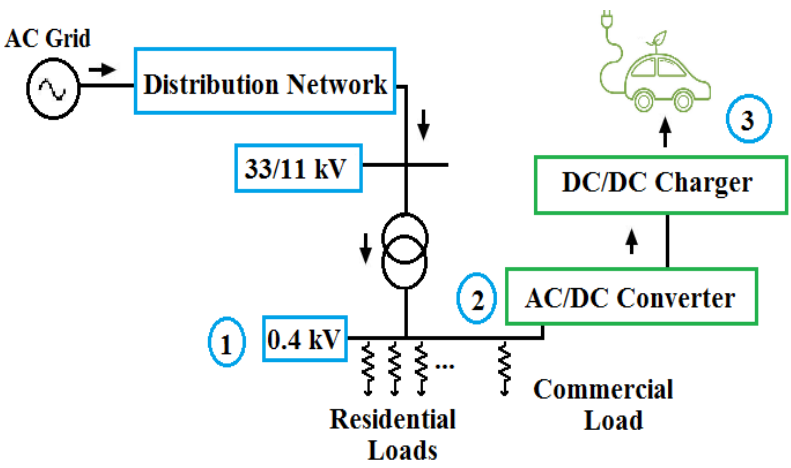

Figure 1: Connection topology and point for DC fast charger.

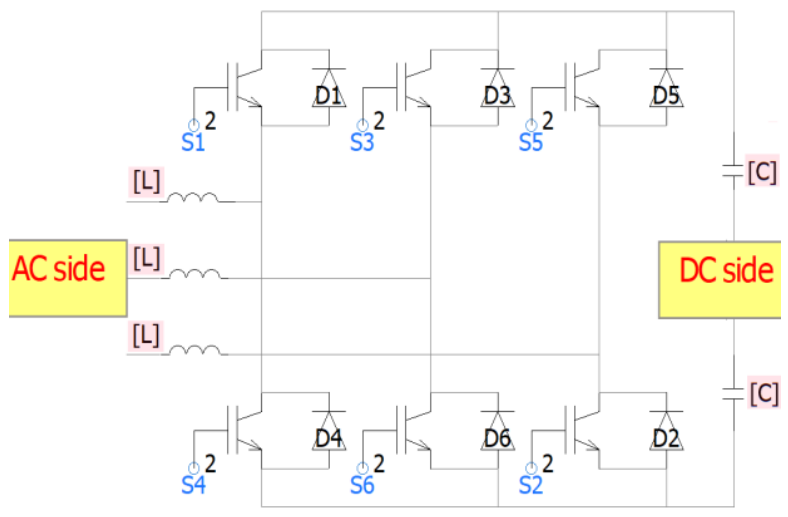

Figure 2: Two-level three-phase VSC topology for AC/DC rectifier.

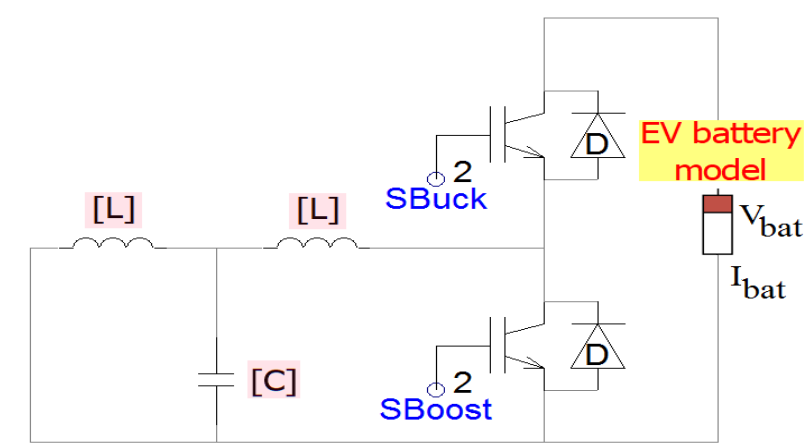

Figure 3: DC/DC charger with a buck-boost DC/DC converter and equivalent battery model.

A buck-boost DC/DC converter with an equivalent battery model is developed to represent the dynamic and transient response of $\mathrm{EV}$ charging. Buck-boost DC/DC converters consist of two switching transistors $\left(\mathrm{S}_{\text {buck }}\right)$ and $\left(\mathrm{S}_{\text {boost }}\right)$ with anti-parallel diodes to enable bidirectional power and current flow. There are two operating principles in buck-boost converters, namely, buck mode to charge the battery, and boost mode to discharge it. The direction of current flow determines whether the battery is charging or discharging. Typically, the converter operates in buck mode and charges the battery if $S_{\text {buck }}$ is switched on and $S_{\text {boost }}$ is switched off, whereas the converter operates in discharging boost mode when $S_{\text {boost }}$ is switched on and $S_{\text {buck }}$ is switched off [22].

There are four main DC fast charger standards in the current market, namely, the Chinese GB/T, the Japanese CHAdeMO, Tesla Superchargers and the Combined Charging System (CCS). These standards draw high power from grids and deliver high DC current to charge vehicles. Currently, the Japanese CHAdeMO standard is publicly the most available option delivering between 50 to $62.5 \mathrm{~kW}$ by $500 \mathrm{~V}$ per vehicle. There is also a revised CHAdeMO version enabling up to 400 kW by 400 A DC [23].

Constant charging and discharging at such high levels may damage and shorten the life of batteries [24-27]. Generally, a constant current-constant voltage (CC-CV) method (see Fig. 4) is applied to control the charging, prolong battery life and prevent battery degradation $[13,22,24]$. In this method, a CC mode is switched to a $\mathrm{CV}$ mode once the battery voltage reaches its upper threshold value, causing the charging current to reduce exponentially while increasing the state of charge (SoC) of the battery $[22,25]$.

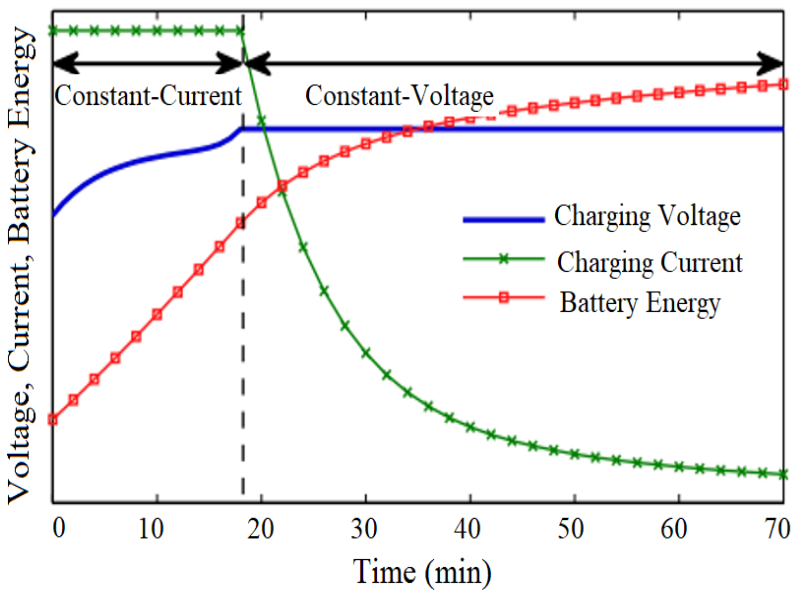

Figure 4: CC-CV method for lithium-ion batteries [25]. 


\section{Modelling OF CASe Studies in A Distribution NETWORK}

This section deals with the modelling of the MV/LV distribution network during maximum and minimum loading conditions. The PSCAD software has been used to implement the model and perform different case studies. The data for the MV/LV network has been provided by Western Power Distribution (WPD) and represents a part of the practical network located in South East Wales.

\section{A. $M V / L V$ distribution network}

The distribution network is connected to the $33 \mathrm{kV}$ grid. Voltage is stepped down to $11 \mathrm{kV}$ by two 15 MVA transformers for the nearest substation. At the $11 \mathrm{kV}$ substation, all voltage levels are stepped down to $0.4 \mathrm{kV}$ with 0.5 MVA transformers. The LV side of the network consists of 63 residential properties and one commercial building connected at different $0.4 \mathrm{kV}$ busbars. The LV network is purely connected by underground cables. Fig. 5 presents the simplified nodal representation of the LV network.

The LV side of the network contains different nodes ( 1 to $15)$ and each node has a different number of consumers with different demand and consumption data. Node 15 represents the only commercial property located in the Southern region of the LV network. Each residential property has an annual energy consumption of $4,000 \mathrm{kWh}$, whereas the commercial building has an annual energy consumption and load factor of $50,000 \mathrm{kWh}$ and $30-40 \%$, respectively.

The number of residential consumers is evenly distributed over the length of the cable in each segment of the LV distribution network. A lumped load at the far-end of each cable is considered and the exact equivalent demand for lumped loads is calculated by taking into account a diversity factor. Equation (1) and Table I are employed to determine the equivalent lumped load demand for each section of the network under maximum and minimum loading, respectively.

$$
P N+Q \sqrt{ } \mathrm{N}=L D
$$

where $P, N, Q$ and $L D$ represent active power, total number of consumers in a group, reactive power, and maximum and minimum lumped demands, respectively. $L D$ values are calculated with maximum and minimum network demand.

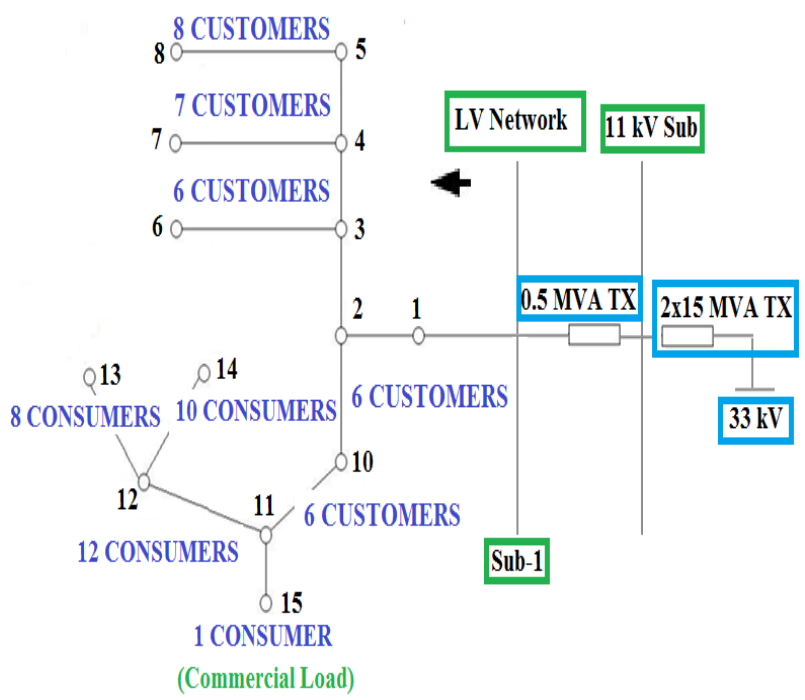

Figure 5: Simplified nodal representation of the MV/LV network.
TABLE I. CALCULATION OF EQUIVALENT LUMPED DEMAND AT MAXIMUM AND MINIMUM LOAD

\begin{tabular}{|c|c|c|c|c|}
\hline Nodes & $\begin{array}{c}\text { Number of } \\
\text { Consumers } \\
\text { (N) }\end{array}$ & $\begin{array}{c}\operatorname{Max} P \& Q \\
\operatorname{Min} P \& Q \\
{[k W]}\end{array}$ & $\begin{array}{c}\text { Maximum } \\
\text { LD } \\
{[\mathrm{kW}]}\end{array}$ & $\begin{array}{c}\text { Minimum } \\
\text { LD } \\
{[\mathrm{kW}]}\end{array}$ \\
\hline $5-8$ & 8 & $\begin{array}{l}1.24 \text { and } 0.74 \\
0.24 \text { and } 0.16\end{array}$ & 12.01 & 2.37 \\
\hline $4-7$ & 7 & $\begin{array}{l}1.24 \text { and } 0.74 \\
0.24 \text { and } 0.16\end{array}$ & 10.64 & 2.10 \\
\hline $3-6$ & 6 & $\begin{array}{l}1.24 \text { and } 0.74 \\
0.24 \text { and } 0.16\end{array}$ & 9.25 & 1.83 \\
\hline $12-13$ & 8 & $\begin{array}{l}1.24 \text { and } 0.74 \\
0.24 \text { and } 0.16\end{array}$ & 12.01 & 2.37 \\
\hline $11-12$ & 12 & $\begin{array}{l}1.24 \text { and } 0.74 \\
0.24 \text { and } 0.16\end{array}$ & 17.44 & 3.43 \\
\hline $12-14$ & 10 & $\begin{array}{l}1.24 \text { and } 0.74 \\
0.24 \text { and } 0.16\end{array}$ & 14.74 & 2.91 \\
\hline $10-11$ & 6 & $\begin{array}{l}1.24 \text { and } 0.74 \\
0.24 \text { and } 0.16\end{array}$ & 9.25 & 1.83 \\
\hline $2-10$ & 6 & $\begin{array}{l}1.24 \text { and } 0.74 \\
0.24 \text { and } 0.16\end{array}$ & 9.25 & 1.83 \\
\hline 15 & 1 & $\begin{array}{l}12.9 \\
5.0\end{array}$ & 12.9 & 5.0 \\
\hline
\end{tabular}

Maximum and minimum lumped demand are calculated for each aggregated residential and commercial group over a period of 24-hours based on load profiles obtained from WPD (see Fig. 6). Nodes 11-12 and 12-14 have a larger number of residential properties (12 and 10, respectively); therefore, a larger equivalent lumped demand is calculated and connected between these points in the network. According to Fig. 6, the commercial node has a higher consumption between the hours of 10:00-16:00, whereas each aggregated residential group has a higher consumption than the commercial building between the hours of 16:00-02:00. Load profiles also show the increase in total network demand if $10-\mathrm{kW}$ chargers were to be replaced with $30-\mathrm{kW}$ chargers between the hours of 07:0009:00 and 17:00-20:00. A worst-case scenario is therefore adopted and $50-\mathrm{kW}$ and $250-\mathrm{kW}$ chargers are assumed to operate during peak hours with maximum network demand.

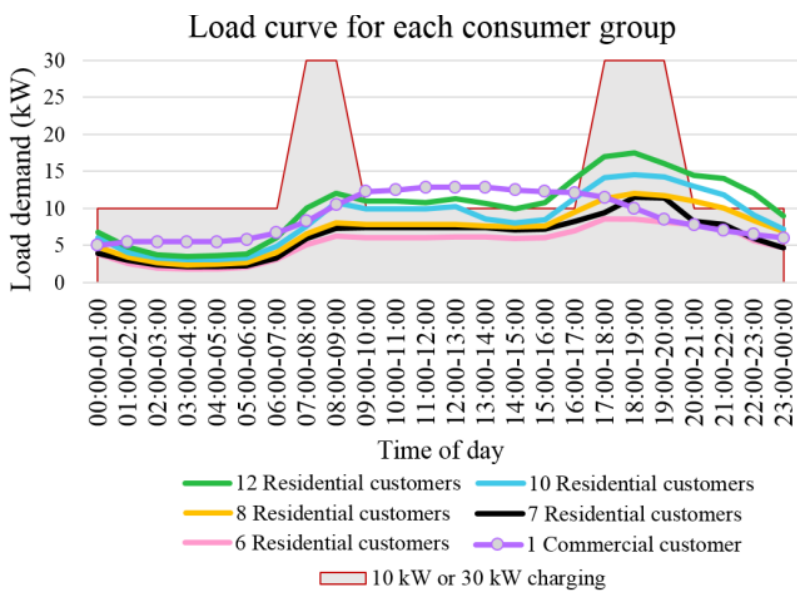

Figure 6: Load profile of lumped consumer groups. 


\section{RESULTS AND DisCUSSION}

The impact of connecting a DC fast charger $(50-\mathrm{kW}$ and $250-\mathrm{kW}$ ) next to a commercial node in the network is assessed. Load curves are used, and voltage profiles and load currents are analysed when the network demand is at maximum (18:00-19:00) and minimum (03:00-04:00) loading conditions. It is assumed that the charging occurs during maximum loading. The implementation of voltage control measures and a V2G technology are considered at a later stage to investigate how challenges in the network can be eliminated or, in the worst case, mitigated.

\section{A. Simulation of battery dynamics during 50-kW charging}

A 50-kW grid-tied three-phase battery system consisting of a DC/DC charger and a bidirectional AC/DC converter and operating at $500 \mathrm{~V}$ DC nominal voltage is modelled near the commercial load at Node 15 to represent the dynamics of fast charging. The characteristics of the $50-\mathrm{kW}$ battery system are illustrated in Fig. 7 and the initial SoC of the battery is assumed to be $50 \%$. The initial stage of the simulation shows that the battery current is high due to a high charging current from the CC mode, whereas the battery voltage is inversely proportional and hence low. Once steady-state is reached, the battery current starts reducing (at $0.25 \mathrm{~s}$ ) and eventually maintains its value at $-96.2 \mathrm{~A}$, while the battery voltage and power reach $520 \mathrm{~V}$ and $-50 \mathrm{~kW}$, respectively. The battery power is negative since the battery is charging and its SoC is increasing due to the $\mathrm{CV}$ mode starting around $0.75 \mathrm{~s}$.

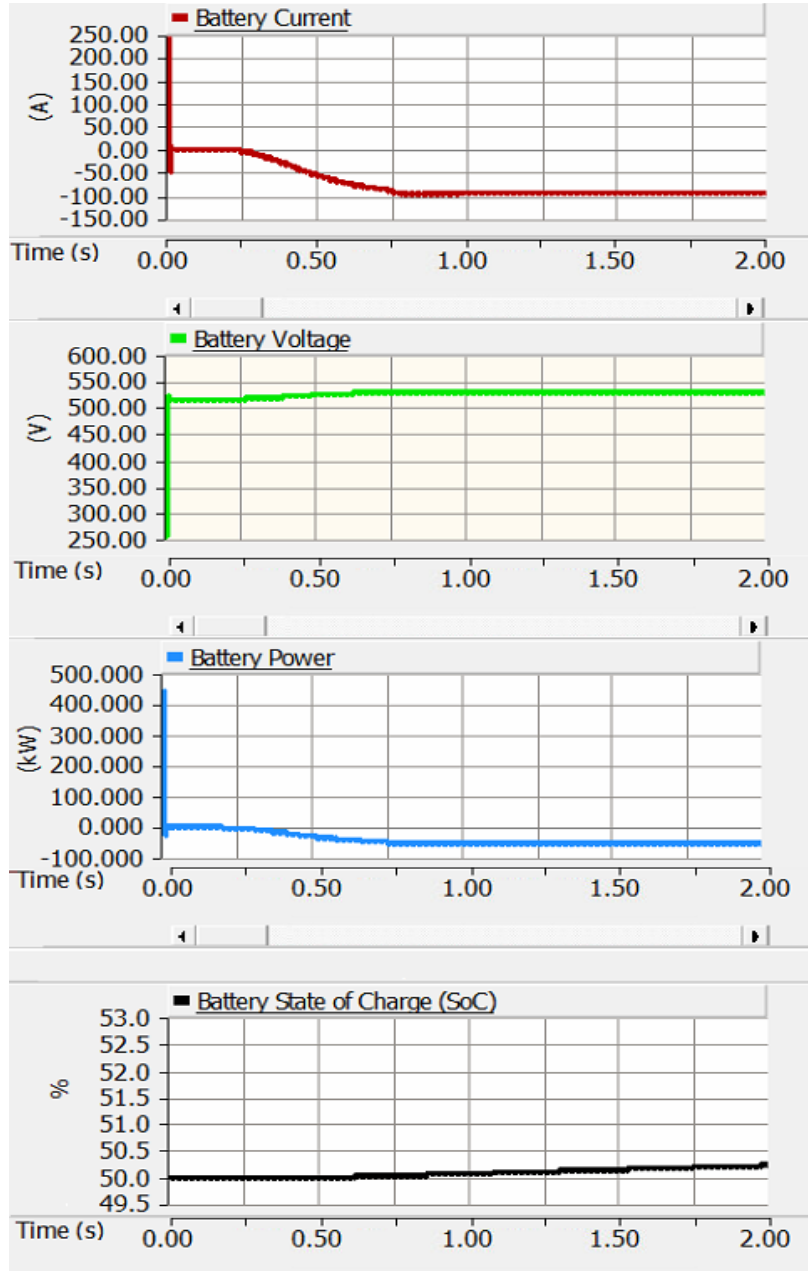

Figure 7: Characteristics of battery current, battery voltage, battery power and battery state of charge during $50-\mathrm{kW}$ constant charging.

\section{B. Impact of 50- $k W$ charger on the LV network profiles}

Voltage changes across busbars in the LV network are investigated with the connection of the $50-\mathrm{kW}$ charger during maximum and minimum network loading. Voltage profiles with and without the charger for both loading conditions are provided in Figs. 8 and 9.

According to Fig. 8, during maximum network demand and loading, all voltage profiles at the LV network experience drops following the connection of the $50-\mathrm{kW}$ fast charger near the commercial load at Node 15 . The maximum and minimum voltage drops are around $5.5 \%$ and $4 \%$ across all LV busbars. The maximum voltage drop occurs at the point of charging, where it drops from 1.066 to 1.008 p.u. According to the Distribution Network Operator (DNO) licence obligation, all busbars connected at the LV must always operate within 1.1 p.u. $(+10 \%)$ and 0.94 p.u. $(-6 \%)$. Therefore, the voltage drops exhibited in this study is acceptable. However, it is worth mentioning that if the size of nearby loads or charger were to increase, or a fast charger was to be connected to a less flexible point in the network, a further voltage drop could become inevitable. In this case, voltage control measures can be provided by DG deployment, static VAr compensator (SVC) connection and on-load tap changer (OLTC) installation for distribution transformers.

According to Fig. 9, during minimum network demand and loading, all voltage profiles at the LV distribution network experience voltage drops with the connection of a $50-\mathrm{kW}$ charger. The results show that the maximum and minimum voltage drops are $5.4 \%$ and $4 \%$ respectively. The maximum drop occurs at the point of charging as before and the minimum drop occurs at Nodes 6,7 and 8 since these are the closest to the main substation and the transformer with taps, and farthest from the point of charging. The voltage results show that the network is more flexible for the connection and deployment of fast chargers during minimum loading.

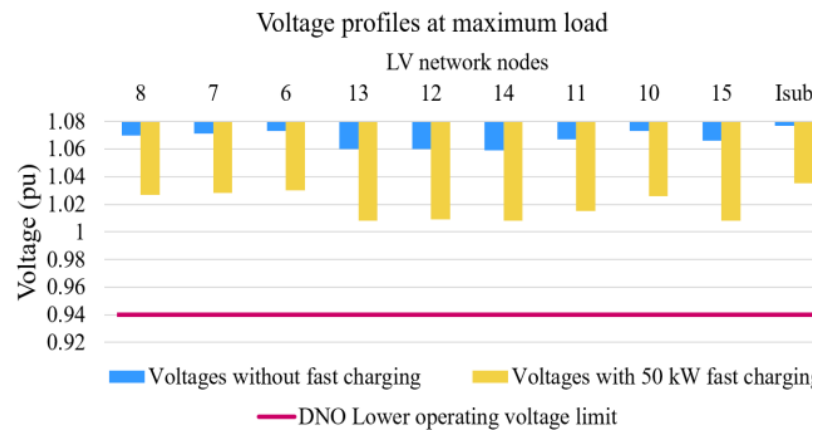

Figure 8: Comparison of voltage profiles with and without $50-\mathrm{kW}$ charger during maximum network loading and demand.

Voltage profiles at minimum load

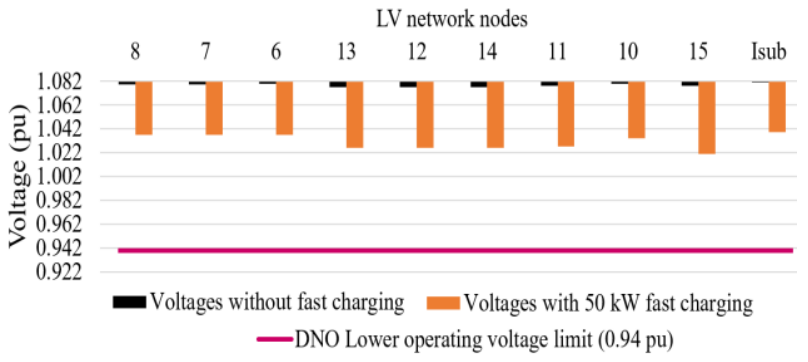

Figure 9: Comparison of voltage profiles with and without 50-kW charger during minimum network loading and demand. 
Current flow at the far-end of each cable and load is also investigated with the connection of a $50-\mathrm{kW}$ charger during maximum and minimum network loading. Results are shown in Figs. 10 and 11.

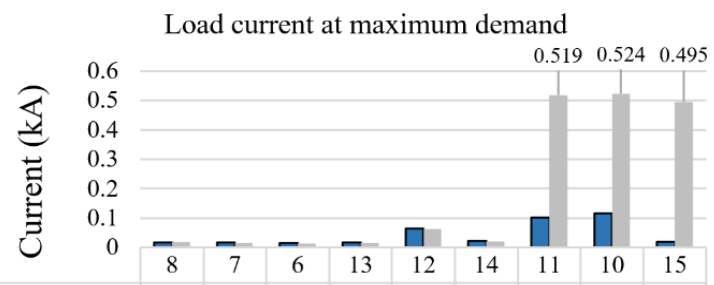

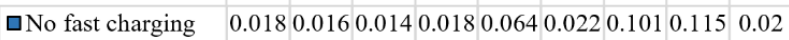
$=50 \mathrm{~kW}$ fast charger 0.0180 .0160 .0140 .0170 .0640 .0210 .5190 .5240 .495

Figure 10: Comparison of RMS currents with and without 50-kW charger during maximum network loading and demand.

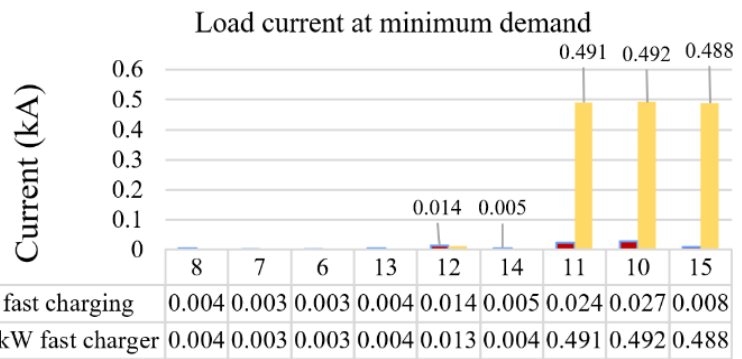

Figure 11: Comparison of RMS currents with and without 50-kW charger during minimum network loading and demand.

Each node draws a higher load current during maximum network loading. The results show that load currents are relatively large at Nodes 10, 11 and 15 during charging as these are the most congested nodes of the LV network. The maximum current rise occurs at the point of charging. On the other hand, these points also experience larger voltage drops and power losses because of the relationship between power and current. Load currents at those three nodes are relatively large even during minimum network loading. This sudden increase in current associated with a larger demand and consumption due to charging may also affect the operation of transformers by causing overheating problems. Two control measures are introduced and implemented to counter possible distribution grid challenges in the next section.

\section{Implementation and comparison of voltage control} measures and $a V 2 G$ in the $L V$ network

The southern region of the network (Nodes 10 to 15 ) is heavily congested since it has larger demand and consumption than the northern region (Nodes 2 to 8). Simulation results showed that the $50-\mathrm{kW}$ fast charger causes large voltage drops and current rises in the southern region of the LV network. In this section, the $50-\mathrm{kW}$ charger is replaced with a $250-\mathrm{kW}$ charger in Node 15, the number of commercial building is increased from one to three in Node 15, and the number of residential properties at Nodes 10, 11 and 12 is doubled to counter affected voltage profiles and increased network overloading and losses during maximum network demand.

Load current, power flow, and voltage profiles are analysed in Nodes 10 to 15 without any control measures. Then, the implementation and modelling of three small-scale DG wind turbine models ( $2.5 \mathrm{~kW}$ each) and V2G system are considered to support the LV network between peak loading hours. The improvement in network voltages, active power flows and current flows are shown in Figs. 12 to 14.

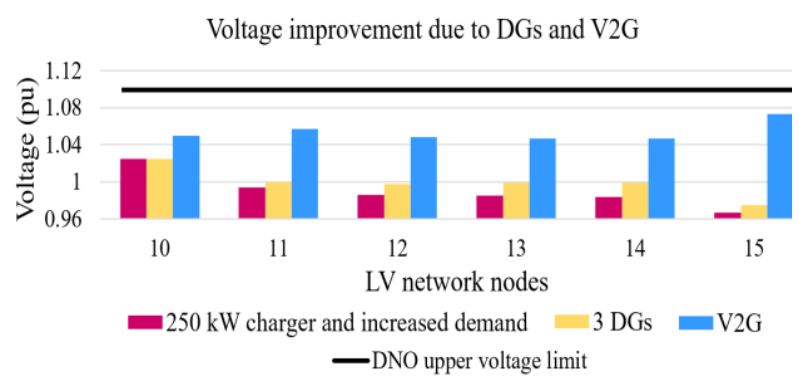

Figure 12: Voltage improvement during maximum network loading with three DG units and V2G system.

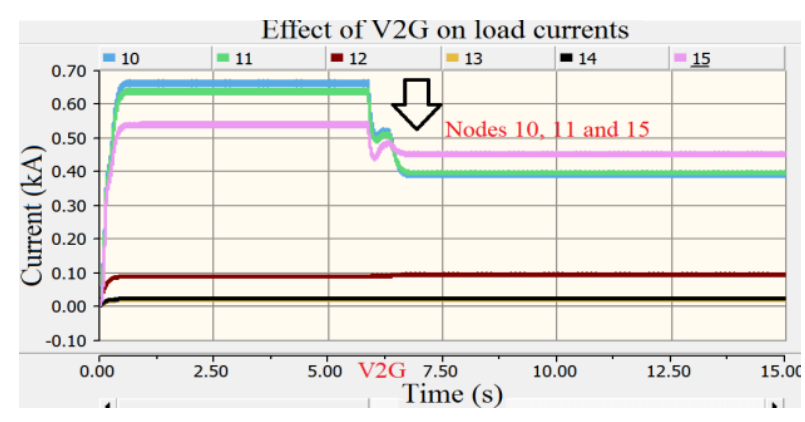

Figure 13: Variation and change in current with V2G enabled at $t=5.8 \mathrm{~s}$.

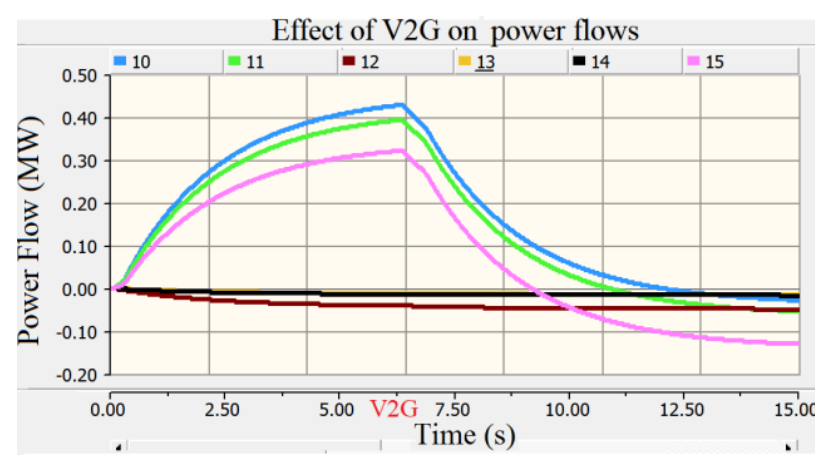

Figure 14: Variation and change in power flow with V2G enabled at $t=5.8 \mathrm{~s}$.

As observed in Fig. 12, the voltage drops are significantly larger in the southern region of the network after the connection of the $250-\mathrm{kW}$ charger near the larger commercial loads. The maximum voltage drop occurs at the point of charging and voltages operate at values closer to the DNO lower limit of $-6 \%$. However, an improvement of up to $1.5 \%$ and $11 \%$ can be achieved in voltage profiles with the implementation of three small-scale DG units and a V2G system, respectively. Once the V2G system is enabled, the $250-\mathrm{kW}$ charger and the battery system export power onto the grid since the direction of current is reversed and the battery system is discharged.

The effects of enabling the $\mathrm{V} 2 \mathrm{G}$ mode at the point of charging at $t=5.8 \mathrm{~s}$ on load currents and power losses are also presented in Figs. 13 and 14. Simulation results show that high load currents and power losses at busbars closer to the charging point (Nodes 10, 11 and 15) can be reduced significantly, which also reduces overloading in distribution network equipment such as cables and transformers.

\section{CONCLUSION}

EVs are not yet fully capable of charging at speeds that are comparable to gas refuelling speeds of ICEVs. Therefore, more sophisticated charging options are necessary to improve 
end-user experience and preserve a smoother traffic operation. Level III public DC fast chargers have been made available for these purposes, with the advantages of reducing range anxiety among drivers, reducing service time at charging stations, and allowing drivers to charge their vehicles freely and whenever they want by increasing access to charging stations located in motorways and shopping malls. However, it is still uncertain whether the existing and future power networks will have an adequate integration and hosting capacity since Level III chargers will increase peak demand and pose some significant challenges, such as increased power losses and network equipment, and other power quality issues. Thus, it is of high importance to ensure that power networks are securely operating within acceptable limits following the connection of thousands of fast/rapid chargers.

In this paper, the dynamics and effects of DC fast charging on a practical $\mathrm{MV} / \mathrm{LV}$ distribution network have been investigated. Simulation results show that the addition of 50$\mathrm{kW}$ and 250-kW chargers near large commercial loads affect the operation and reliability of the LV network unless adequate or smart control measures are implemented during peak network demand. The results show that fast charging affects voltage profiles, increases load current, power losses and network overloading, and modifies power flows. Furthermore, connecting chargers with a higher power requirement in congested regions of the network causes larger voltage drops and current rises in the LV side of the network.

Given the increased voltage drops and current rises when a $250-\mathrm{kW}$ charger is considered together with an increased network demand, necessary control measures have been introduced by the implementation of three small-scale DG units and a V2G system to counter and mitigate possible distribution grid challenges during maximum network loading conditions. The results show that V2G can achieve a voltage improvement of up to $11 \%$ and a current reduction of up to $40 \%$ at the point of charging. Moreover, V2G can also improve voltages by up to $8-9 \%$ higher compared to the deployment of the three small-scale DG units. However, installing DG of larger capacity can also be effective at improving grid-side challenges.

\section{REFERENCES}

[1] M. B. Arias, M. Kim and S. Bae, "Prediction of electric vehicle charging power demand in realistic urban traffic networks," Applied Energy, vol. 195, pp. 738-753, Jun. 2017.

[2] I. Zenginis, J. S. Vardakas, N. Zorba and C. V. Verikoukis "Analysis and quality of service evaluation of a fast charging station for electric vehicles," Energy, vol. 112, pp. 669-678, Oct. 2016.

[3] International Energy Agency, Global EV Outlook 2018: Towards cross-modal electrification; 2018.

[4] D. Efthymiou, K. Chrysostomou, M. Morfoulaki and G. Aifantopoulou, "Electric vehicles charging infrastructure location: a genetic algorithm approach," European Transport Research Review, vol. 9, no. 2, May. 2017.

[5] O. Sassi and A. Oulamara, "Electric vehicle scheduling and optimal charging problem: complexity, exact and heuristic approaches," International Journal of Production Research, vol. 55, pp. 519-535, Jan. 2017.

[6] D. Meyer and J. Wang, "Integrating ultra-fast charging stations within the power grids of smart cities: A review," IET Smart Grid, vol. 1, pp. 3-10, 2018.

[7] F. d. P. García-López, M. Barragán-Villarejo and J. M. Maza-Ortega, "Grid-friendly integration of electric vehicle fast charging station based on multiterminal DC link," Electrical Power and Energy Systems, vol. 114 , pp. $1-15,2020$.
[8] B. Sun, T. Dragicevic, F. D. Freijedo, J. C. Vasquez and J. M. Guerrero, "A control algorithm for electric vehicle fast charging stations equipped with flywheel energy storage systems, " IEEE Transactions on Power Electronics, vol. 31, pp. 6674-6685, Sep. 2016.

[9] P. Phonrattanasak and N. Leeprechanon, "Optimal placement of EV fast charging stations considering the impact on electrical distribution and traffic condition," in 2014 International Conference and Utility Exhibition on Green Energy for Sustainable Development, pp. 1-6.

[10] A. Meintz, et. al., "Enabling fast charging - Vehicle considerations," Journal of Power Sources, vol. 367, pp. 216-227, 2017.

[11] K. Yunus, H. Z. De La Parra and M. Reza, "Distribution grid impact of plug-in electric vehicles charging at fast charging stations using stochastic charging model," in Proc. $201114^{\text {th }}$ European Conf. on Power Electronics and Applications, pp. 1-11.

[12] V. M. Iyer, S. Gulur, G. Gohil and S. Bhattacharya, "Extreme fast charging station architecture for electric vehicles with partial power processing," in 2018 IEEE Applied Power Electronics Conference. and Exposition, pp. 659-665.

[13] C. H. Dharmakeerthi, N. Mithulananthan and T. K. Saha, "Impact of electric vehicle fast charging on power system voltage stability," International Journal of Electrical Power and Energy Systems, vol. 57, pp. 241-249, May. 2014.

[14] A. Lucas, F. Bonavitacola, E. Kotsakis and G. Fulli, "Grid harmonic impact of multiple electric vehicle fast charging," Electric Power Systems Research, vol. 127, pp. 13-21, 2015.

[15] H. B. Sonder, L. Cipcigan, C. E. Ugalde-Loo, "Using electric vehicles and demand side response to unlock distribution network flexibility," IEEE PES PowerTech Milano Conference, 2019.

[16] E. Akhavan-Rezai, M. F. Shaaban, E. F. El-Saadany and A. Zidan, "Uncoordinated charging impacts of electric vehicles on electric distribution grids: normal and fast charging comparison," IEEE Power and Energy Society General Meeting, pp. 1-7.

[17] B. Pea-Da and S. Dechanupaprittha, "Impact of fast charging station to voltage profile in distribution system," in 2014 International Electrical Engineering Congress (IEECON), pp. 3-6.

[18] S. Alshareef and W. Morsi, "Impact of fast charging stations on the voltage flicker in the electric power distribution systems," IEEE Electrical Power and Energy Conference (EPEC), 2017.

[19] P. Sadeghi-Barzani, A. Rajabi-Ghahnavieh and H. Kazemi-Karegar, "Optimal fast charging station placing and sizing," Applied Energy, vol. 125, pp. 289-299, 2014.

[20] M. Yilmaz and P. T. Krein, "Review of the impact of vehicle-to-grid technologies on distribution system and utility interfaces," IEEE Transactions on Power Electronics, vol. 28, pp. 5673-5689, 2013.

[21] R. Shi, X. P. Zhang, D. C. Kong, N. Deng and P. Y. Wang, "Dynamic impacts of fast-charging stations for electric vehicles on active distribution networks," 2012 IEEE PES Innovative Smart Grid Technologies (ISGT) ASIA, pp. 1-6.

[22] G. Angelov, M/ Andreev and N. Hinov, "Modelling of electric vehicle charging station for DC fast charging," $201841^{\text {st }}$ International Spring Seminar on Electronics Technology (ISSE), pp. 1-5.

[23] B. Morris, L. Michela and Y. Wahiba, "Modelling and simulation of electric vehicle fast charging stations driven by high speed railway systems," Energies, vol. 10, pp. 1268-1291, Sep. 2017.

[24] J. Y. Yong, V. K. Ramachandaramurthy, K. M. Tan, A. Arulampalam and J. Selvaraj, "Modeling of electric vehicle fast charging station and impact on network voltage," in 2013 IEEE Conference on Clean Energy and Technology (CEAT), pp. 399-404.

[25] P. Fan, B. Sainbayar and S. Ren, "Operation analysis of fast charging stations with energy demand control of electric vehicles," IEEE Transactions on Smart Grid, vol. 66, pp. 1819-1826, Jul. 2015.

[26] O. Veneri, L. Ferraro, C. Capasso and D. Iannuzzi, "Charging infrastructures for EV: Overview of technologies and issues," Electrical Systems for Aircraft, Railway and Ship Propulsion (ESARS), pp. 0-5, 2012.

[27] T. C. Huang, R. H. Peng, T. W. Tsai, K. H. Chen, C. L. Wey, "Fast charging and high efficiency switching-based charger with continous built-in resistance detection and automatic energy deliver control for portable electronics," Journal of solid-state circuits, vol. 49, pp. 15801594, Jul. 2014. 